\title{
MAPPING THE INFORMATION SYSTEM DEVELOPMENT PROCESS
}

\author{
Richard Vidgen ${ }^{1}$, Sabine Madsen ${ }^{2}$, and Karlheinz Kautz ${ }^{2}$ \\ ${ }^{I}$ School of Management, University of Bath, UK; ${ }^{2}$ Department of Infomatics, Copenhagen \\ Business School, Denmark
}

\begin{abstract}
Action research is used to gain understanding of how an IS development methodology emerges in practice and how it can contribute to value creation in organizations. The Multiview framework is used to guide the action research project. A graphical notation for mapping the unfolding of IS development projects is developed and applied to the project. Reflection on the project leads to a number of lessons being drawn about the organization of the IS development process, addressing themes such as vision, time pacing, and the role of architecture. The paper concludes with ideas about how the theoretical underpinnings of IS development might be bolstered by complex adaptive systems.
\end{abstract}

Key words: Action research, Multiview, IS development, Process mapping, Complexity

\section{INTRODUCTION}

A number of methodology authors recommend that the development process is tailored to fit the contingencies of the particular situation (Avison et al., 1998; Jacobsen et al., 1999) and empirical studies show that in practice the methodology is uniquely enacted for every development project (Stolterman, 1994; Fitzgerald, 1997). System developers adapt and apply methods and methodologies in a pragmatic way. A recent study indicates that this is also the case in web-based IS development (Baskerville \& PriesHeje, 2001), but so far little research has addressed the issue of how a local methodology is constructed, how it emerges in practice, and how effective it is in terms of creating value for the host organization. This paper presents an action research project in which the Multiview/WISDM framework (Vidgen et al., 2003) was used to guide the development of a market research data 
repository for a UK-based small to medium enterprise (SME). The aim of the paper is to show how the method emerged in practice and to reflect on that emergence in order to draw lessons about system development practice and theory.

\section{RESEARCH DESIGN}

\subsection{Action research}

Action research was chosen as the primary research method in order to learn from first-hand experience how an IS development methodology (ISDM) emerges, i.e., the practice rather than the formalized descriptions given in text books and by method authors (Avison et al., 1999). The roots of action research can be traced back to Lewin's (1948) work on social change and social conflicts, through the Tavistock Institute's work on sociotechnical theory (Emery and Trist, 1960), Checkland's (1981) view of human activity systems, to the Multiview/WISDM framework (Avison and Wood-Harper, 1990; Vidgen, 2002).

In their exposition of canonical action research, Davison et al. (2003) present arguments for and against the principle of theory. The counter arguments to using theory in action research are, firstly, it is difficult for the researcher to know what theory will be used or developed (particularly at the start of a project) and, secondly, there may be social issues arising for which no paradigmatic model exists. However, Davison et al. (ibid.) conclude that theory plays an essential role in guiding project activities and thus in distinguishing action research from action learning. Checkland (1991) also claims that the definition of a framework of ideas is important if action research is to be rigorous and have validity - it also helps differentiate action research from consultancy (Baskerville and Wood-Harper, 1996). Multiview/WISDM is used in this research to provide a structure for guiding action and as a basis for describing the unfolding of the project.

\subsection{Multiview}

Conventional systems analysis approaches, such as structured systems analysis, data modelling, and object-oriented methods, emphasize 'hard' aspects of the problem domain, that is, the certain and the precise (Avison and Fitzgerald, 2002). A hard approach is prescriptive and might be applied fairly consistently between organizations and within organizations. Checkland (1991) argues that systems analysts need to apply their craft to 
problems set in the ill-structured, fuzzy world of complex organizations. What makes organizations so complex and different is people - very different in nature from the data and processes that are emphasized in conventional IS development methods. People have different and conflicting objectives, perceptions and attitudes; people change over time. This may explain some of the dissatisfaction with conventional information systems development methodologies, i.e., they are not addressing the reality of organizational life.

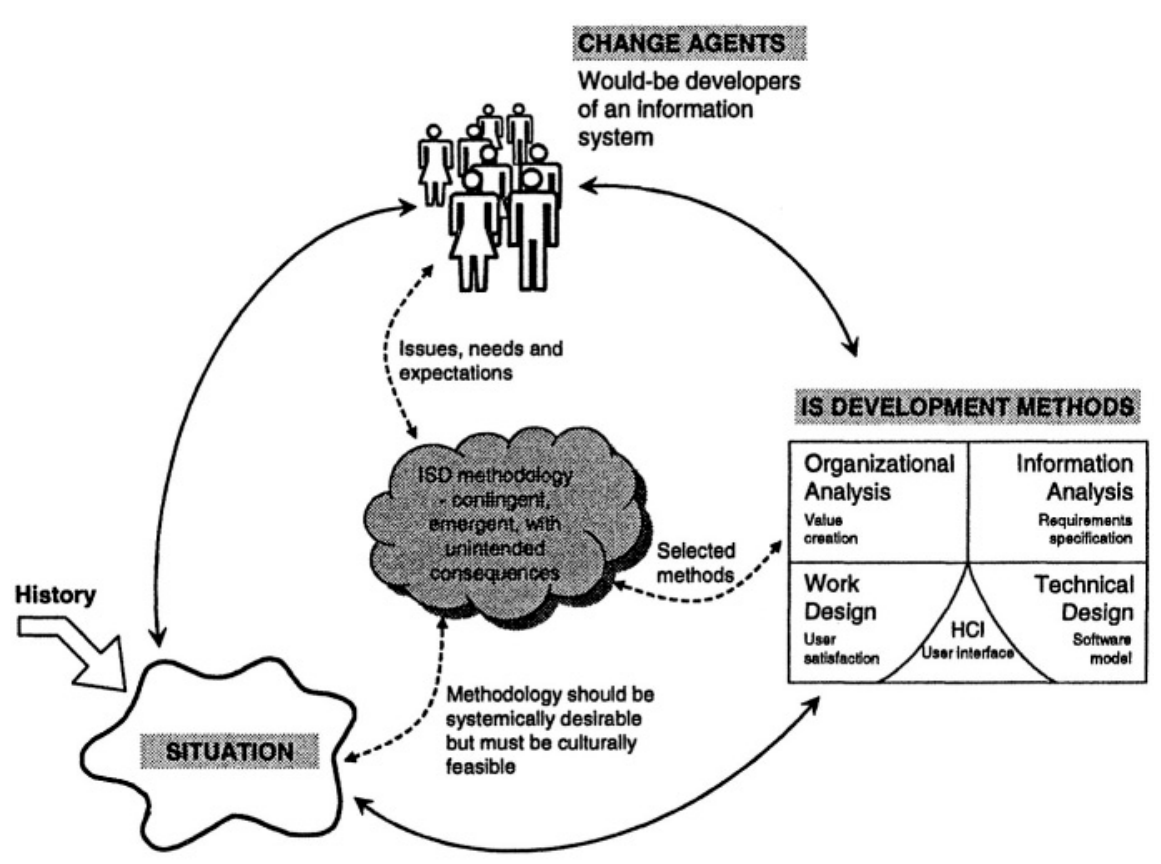

Figure 1. The Multiview framework (adapted from Vidgen et al., 2003).

Multiview is a systems development framework that has been defined and redefined over many years. It was espoused originally in Wood-Harper et al. (1985), developed further in Avison and Wood-Harper (1990) and Avison et al., (1998) with its latest reincarnation to be found in Vidgen et al. (2003). Multiview proposes that information systems development is a process of mediation between five elements: organizational analysis, information analysis, work design, technical design, and human-computer interface design (figure 1). The IS development activity is undertaken by human change agents with individual and shared interests in a particular organizational context with a distinct culture and history. Multiview draws on different tools and techniques into a blended approach. Each of these tools and techniques is used contingently, that is, as appropriate for each 
different problem situation. Even after some twenty years of refinement, Multiview is best described as a framework, not a step-by-step methodology, and its use as an 'exploration of information systems development' rather than the application of a prescriptive approach. Thus, according to the Multiview approach an IS development methodology is emergent only in practice through the complex interaction of change agents (including system developers) and development methods in an organizational setting. Multiview is, therefore, more usefully seen as a metaphor that is interpreted and developed in a particular situation, rather than as a prescriptive description of some real-world activity (Watson and Wood-Harper, 1995).

\subsection{The client organization}

Founded in 1991, Zenith International Ltd is a business consultancy specializing in the food, drinks and packaging industries worldwide. The main business activities are market analysis, strategic advice, technical consulting projects and conference organization. In spring 1998, the strategic aims of Zenith were to create a global presence, to broaden the product range, and to develop complementary skills (e.g., a synergy of market intelligence reports and consultancy). In September 1998 Zenith launched its first Web site, a typical cyber-brochure with limited interaction facilities.

The success of the company Web site launched in 1998 gave Zenith the confidence to explore e-commerce and the online delivery of market research content. In October 1999 Zenith and the University of Bath established a two-year joint project under the Teaching Company Scheme (TCS) with the objective of building an e-commerce system for selling research data on global drinks consumption (see Vidgen, 2002 for a full account).

The area of application for the action research reported here was a second TCS initiative, running for two years from October 2001, with the aim of creating a market research data repository (MRDR) that would contain details of companies and production volumes in the drinks industry. The primary action researcher worked in the role of Academic Supervisor for the project and was involved in hands-on development in the early stages of the MRDR. A second researcher was involved as an 'action case' researcher (Braa \& Vidgen, 1999) for six months on the project, contributing primarily to the information analysis activity. A third researcher acted as an independent observer and conducted interviews with employees of the case organization, as well as with the action researcher and the action case researcher. This supplementation of action research by case study was chosen to bring more interpretive rigour to the project. 


\section{THE INTERVENTION}

The setting for the MRDR project was Zenith's market research department, which consists of six full time employees, including the Market Research Director. Each year the department produces a number of market reports, with the two most important ones being the 'Bottled Water' and 'Water Coolers' reports. The reports are based on data gathered from as many companies as possible in a line of business, such as bottled water. The reports are then sold to companies in the drinks industry, such as manufacturers (who provided the original detail data), packagers, and distributors. From initiation to publication, each report takes around three to four months to produce. Each report is led by a single market researcher who does the bulk of the work and gains a deep insight into the data and manages the structure of the report. A large volume of data has to be collected, stored and processed and information overload is the norm: "We've got loads of information on paper, on Excel files, all floating around" (Market researcher). A number of different software tools, such a Excel, Powerpoint and Word are employed in creating and formatting the reports:

We use Microsoft Office essentially, Excel predominantly, PowerPoint to create charts and it is an extremely laborious process... For the 10 to 11 years the company has been going, we have produced company profiles in Excel format, we have linked each profile to overview tables and have created charts manually in PowerPoint, because that was the best presentation method at that time. Charts then pasted from PowerPoint, pictures into Word and put it all together using these packages. Obviously, this is extremely time-consuming. (Market Researcher)

The vision for the project, as documented in the project proposal, was clear from the outset: "to develop a unified market research data repository (MRDR) for the benefit of internal and external users encompassing data entry, data analysis, and report generation". The Market Research Director envisaged efficiency savings of up to $50 \%$ in market research report production time through the removal of labour intensive activities such as data entry and report formatting. The saving on clerical time would allow researchers to spend more time on data analysis and commentary, thus adding value to the basic report data (business effectiveness in addition to efficiency). In the larger context, a unified MRDR would allow data to be analyzed across reports, to create new revenue streams, to support consulting assignments, and to generally create a platform for greater organizational flexibility.

The development approach specified in the project proposal was incremental prototyping followed by pilot implementation of a single market 
report encompassing data collection, data analysis, and report production. The MRDR would then be rolled out for further market reports and external access to reports and ad hoc queries would be made available to clients via the Internet. Technically, the project was expected to make use of the new generation of content management software (CMS) (Goodwin and Vidgen, 2002). The incremental prototypes would be produced on a six week timeboxed basis, allowing frequent delivery of product to users and thus building credibility and keeping communications open. The plan was for the content of the deliverables to be constrained by the time available, as proposed in agile software development (Highsmith, 2002).

\subsection{The project organization}

The two year TCS programme (October 2001 - October 2003) was intended to develop the skills of the Teaching Company Associate, who was a recent MSc Computer Science graduate, to transfer knowledge from the academic institution via the Academic Supervisor to the company, and to achieve a tangible business benefit for the company. The Associate was employed on a full-time basis by the University for the two-year life of the project, but based in the company's offices taking day-to-day direction from the Industrial Supervisor, who was the Market Research Director at the company. These three - Associate, Academic Supervisor, and Industrial Supervisor - formed the core of the MRDR project team. The Market Research Director at Zenith also took the role of programme facilitator and was thus the business sponsor and internal champion for the project.

The formal organization of the MRDR project under TCS guidelines required regular steering committee meetings and technical meetings. Steering committee meetings were held every four months and attended by the Chairman of the company, a representative of the Teaching Company Directorate, and all the members of the project team. Technical meetings were held monthly by the project team to review progress and to document actions and decisions. The trust between Zenith's Chairman and the project team is illustrated clearly:

Once a month is a working technical meeting, which I receive the minutes of. But I don't have an influence on that. And the reason why I don't, is that they are all very good, they know what they are doing and I can't contribute. I can contribute at the broader level and just reassure myself that the project is going well, but because they are a particularly good team, they are getting on with it and I'm happy with that. (Chairman, Zenith). 


\subsection{The unfolding of the project}

The project phases are summarized in table 1 . Narrative has been used to present the case, but it is difficult to discern a pattern to the unfolding of the development methodology from text. Langley and Truax (1994) note that longitudinal process research generates large quantities of data and that Miles and Huberman (1984) recognize the usefulness of visual displays. The presentation in table 1 is, of course, a vastly simplified presentation of the project; a severe condensing of interviews, research diaries, project documents, and so on. One way of presenting the unfolding of this project and to discern the shape from a morass of detail is to present the research using a process map.

The notation used in figure 2 takes elements from Langley and Truax's (1994) process flow chart and Thorp's (1998) results chain modelling, with the addition of further notation to make an explicit connection between the Multiview framework in figure 1 and the process map. The notation used in figure 2 is as follows.

Square-edged boxes represent initiatives. Initiatives are labelled according to the Multiview methods matrix: $\mathrm{OA}=$ organizational analysis, $\mathrm{IA}=$ information analysis, $\mathrm{WD}=$ work design, $\mathrm{TD}=$ technical design, $\mathrm{HCI}=$ human computer interface design. SD is used to indicate software development. Rounded boxes represent outcomes. Solid horizontal arrows represent precedence and influence, but not necessarily cause and effect. Three weights of line are used to show different strengths of connection the thicker the line the more influential the connection. A zig-zag line is used to show an initiative that has been terminated or is temporarily in abeyance.

A lozenge symbol is used to indicate a reorienting impact. Hexagons represent assumptions that drive initiatives. Ovals represent perturbations events that are outside the control of the system (part of the environment). Dotted vertical arrows connect the assumptions and events to relevant initiatives. A plus sign (+) indicates that the connection is facilitating and a minus sign (-) that it is inhibiting.

From the initiatives and outcomes in figure 2 it is possible to identify the major phases that emerged in the project: exploration; development of database; investigation of business process/job satisfaction; design of software architecture and development of core operational software; live use of software to produce market reports; extension of software (e.g., Internet access by clients to MRDR). The project used the Multiview framework to guide the project activities but the detailed content and the timing were emergent from the interplay of the actors, the situation, and the methods. The phases were only identifiable with the benefit of hindsight, i.e., as a result of the process mapping exercise. 
Table 1. The MRDR project activities

\begin{tabular}{cl}
\hline Time period & Activity \\
\hline Oct $2001-$ & $\begin{array}{l}\text { Initiation: developer trained in technology used by Zenith; review of content } \\
\text { management software (CMS) conducted resulting in decision to custom build } \\
\text { Jan } 2002 \\
\text { solution. }\end{array}$ \\
Feb $2002-$ & Database modelling $\cdot$ database is recognized as core to MRDR. The plan
\end{tabular}

Jul 2002 allowed for six weeks elapsed time to design database on the assumption that a CMS would be implemented - due to the complexity of the MRDR data structures analysis and design took five months to reach a stabilized database.

Apr 2002 - HCI development 1: an early prototype was developed to provide the users May 2002 with a tangible output, allowing feedback on look and feel and a first test of the database structure.

May 2002 - Formal requirements analysis: the informal notes and analysis of business Jun 2002 processes were written up using flow charts and UML use cases.

Jul 2002 Job satisfaction investigation: application of the Multiview framework suggested that attention be given to job satisfaction of market researchers. The ETHICS questionnaire was rejected by the human resources manager (see Vidgen and Madsen (2003) for a full account). A revised questionnaire combining job satisfaction and use cases was developed and this highlighted that users felt they spent too much time collecting and formatting market data as opposed to analyzing, summarizing, and commenting.

Aug 2002 - Technical architecture: the original three-tier architecture was superceded by Dec 2002 a four-tier architecture based on XML. This was a response to the complexity of the MRDR application and the desire to build a flexible platform for data sharing.

Sep 2002 - Development of company detail reports: the emphasis of the project was on Jan 2003 Web delivery, but Zenith's Chairman wanted the MRDR to produce an exact facsimile of the current paper reports. This required the introduction of a more sophisticated formatting technology, XML-FO (formatting objects), to deal with page headers, page breaks, etc. for output in PDF format.

Jan 2003 - HCI development 2: the Market Research Director of Zenith needed a Feb 2003 deliverable from the MRDR project to sustain interest and credibility within Zenith. If data company detail data were entered into the database then a directory of companies in the water cooler industry could be generated. To support data entry of company detail data the user interface was redeveloped.

Mar 2003 - Water cooler company directory: Company data entered into the database, May 2003 the water cooler directory report produced automatically in PDF format, and marketed and sold to clients.

Jun 2003 - Market summary analysis: detailed company volume data summarized into Jul 2003 market overviews (e.g., top 50 bottled water companies in Europe).

Jul 2003 - HCI development 3: testing of interface with users identifies extensive Sep 2003 modification needed to support needs of market researchers in the production of live reports.

Oct 2003 - Market report production: the first full market report, West Europe Bottled Jan 2004 Water, is produced using the MRDR.

Feb 2004 Extension: further reports produced from the MRDR, external access via the onward Internet, and new business initiatives. 


\section{LEARNING FROM THE INTERVENTION}

The explicit specification of learning through reflection is where action research can make a contribution to practice and to theory. The key lessons that have arisen throughout an on-going process of reflection and a subsequent analysis of the process map (figure 2) are now summarized.

\subsection{Projects need a vision}

With regards to organizational analysis and value creation (figure 1), the research underlines the need for information system development projects to have a clearly articulated vision that is couched in terms of the value to be created for the organization (Vidgen, 2002). Highsmith (2000) calls this the project mission - "anything that helps the project team define the desired results of the effort at a summary level" (p. 44). Success is then judged on the basis of how well the vision is achieved, not by how well the plan was implemented. With regard to the MRDR, the project description on the cover page of the project proposal gave a clear statement of the vision:

To create an enterprise repository for Zenith's research data, using a web content management software solution, to support internal knowledge development and external sales of research data. (TCS Project Proposal)

This vision remained constant throughout the project, because it focussed mainly on 'what' was to be achieved in broad terms, and provided a sense of direction whenever there was a danger of the project drifting or becoming mired in technical issues. However, by including a statement of 'how' this would be achieved, i.e., through the use of content management software, the clarity of the vision in the project proposal was weakened. At any given level of recursion the vision should address the 'what' rather than the 'how'. A similar approach is suggested in more mainstream strategy planning by Kaplan and Norton (1993) who proposed the balanced scorecard. The balanced scorecard contains a vision and mission statement together with a set of critical success factors and a small number (around sixteen) of relevant measures. The action research project was evaluated in financial terms (a requirement of TCS funding) but clearly a balanced scorecard approach could have been taken to broaden the evaluation criteria to include aspects such as job satisfaction.

\subsection{Frameworks provide guidance, not prescription}

By organizing around a vision, an IS project needs to be guided toward a desirable outcome rather than pursue a planned result. Although 
methodology as contingent and locally situated practice might be described as amethodical, this does not mean that it is a series of random actions (Truex et al., 2000). The project reinforced the value of the Multiview framework as an aid to guiding the system development process and influencing mental models rather than a prescription. For example, the value of using Multiview as a guide was illustrated in the project by the investigation of work life quality and the subsequent development of the use case job satisfaction instrument. Without a guiding framework it is quite likely that the sociotechnical aspect of systems development would not have been addressed at all.

Related to the idea of Multiview as guiding framework, we found that the outline project plan was perceived to be more valuable than the detailed Gantt chart. A Gantt chart was produced because it was required for the steering committee meetings, but the (over-)detailed plan was symbolic rather than of practical use in managing and controlling the project. Gantt charts may indeed be useful but they need to be specified at a level of detail suitable to the task in hand and then black-boxed for higher levels of the project organization structure; the steering committee was not interested in the fine-grain project detail and neither did the Gantt chart help the project team organize their day-to-day work.

\subsection{Architectures help manage complexity}

Technical architectures are useful in technical design as a way of managing complexity. Although agile software developers prefer to 'keep it simple' and prefer to avoid building infrastructure, this approach can lead to the developers being overwhelmed by the complexity of the software. In this project, the evolution of a four-tier architecture based in XML allowed separation of database, stored procedures to transform the data, components for encapsulation of business rules, and a presentation layer to deal with delivery to different platforms (e.g., web browser, paper, spreadsheets, and OLAP tools). However, the architecture should be a response to the complexity of the situation and not a fixed structure. We planned for a threetier architecture but found that four layers were needed to cope with the inherent complexity of the application.

\subsection{Time-pacing rather than time-boxing}

The agile method Scrum comprises 30 day iterations called 'Sprints' (Highsmith, 2002). We found that such a pace was impossible to maintain, which can be attributed to an inexperienced developer (the TCS Associate), the introduction of leading edge technology (XML-FO in particular), the 
need to develop project infrastructure (the four-tier architecture), and a relatively complex database structure. However, we do not conclude from this that the agile principle of fast and regular delivery is inappropriate. Brown and Eisenhardt (1998) talk about 'time-pacing' as an internal metronome that drives organizations according to the calendar, e.g., "creating a new product every nine months, generating $20 \%$ of annual sales from new services" (p. 167). Time pacing requires organizations to change frequently but interestingly can also stop them from changing too often or too quickly. Time pacing is therefore not arbitrary; rhythm is used by organizations to synchronize their clock with the marketplace and with the internals of their business (although Brown and Eisenhardt give no indication as to how an organization might set the pace of the internal metronome). Although it is quite possible that the 30 day Sprints in Scrum are an institutionalization of best practice time-pacing of system development it is also possible that different situations with different developers, skills and organizational contexts will need to find their own rhythm. The idea of forced IS delivery through time-pacing is an interesting one with many implications for the IS development process and future research.

\subsection{No 'one' is in control}

With regard to the unfolding of the project as mapped in figure 2 it is difficult to say precisely how and why the IS development structure ended up as it did. It seemed that the project shape emerged from the interplay of the team members and their responses to external perturbations. Streatfield (2001) presents the traditional view of managers as 'in control' as selecting, designing, planning a course of action, correcting deviation, working in a stable environment with regular patterns, conformity, and consensus forming. Streatfield (ibid.) continues with the 'not in control' view, which sees action as evoked, provoked, emerging, amplifying deviation, and an unstable and unpredictable environment with diversity and conflict (figure 8.2, p. 134). Rather than accept one or other of these poles managers must work with the paradox of control. They have to accept the anxiety that is generated, using gesture-response as part of the subjective interaction in groups and help all organizational members look for meaning in the living present while perpetually constructing the future.

The implication of this view is that IS project managers should accept and even embrace the paradox of control, i.e., they are simultaneously 'in control' and 'not in control' and need the courage to live with the resulting anxiety. This view of control as emergent seems to describe well the experience of the MRDR project. On a day to day basis much of the control 
was in the hands of the Associate, but there were also hierarchical influences from the Academic Supervisor concerning the technology and development methods, and from the Industrial Supervisor with regard to business issues. The mix of control also changed over time as the Associate gained technical skills and confidence in her abilities. Thus, it is difficult to say who was in control of this project in a traditional managerial sense; control was an emergent property and outcome rather than a causal input.

\section{SUMMARY}

The emergent IS development methodology used to build a market research data repository (MRDR) through action research was mapped using a graphical notation. This style of presentation allowed a two year project to be presented succinctly in a one page diagram (figure 2). Despite the danger of over-simplification, we believe this approach to presenting the results of action research provides a basis for comparing multiple projects and identifying common themes such that the dynamics of method emergence in practice can be better understood.

Using the process map reflection on the lessons from the action research project led to a number of themes: the need to articulate and organize around a vision, the use of Multiview as a guide to action, the role of technical architecture in managing technical complexity, time-pacing and the internal metronome of system development, and the paradox of control. An underlying theme to all these lessons is a response to complexity. Agile software development as proposed by Highsmith (2000) draws much on complex adaptive systems theory, key features of which are selforganization and emergent order, the dispersion of control, and the presence of internal mental models that contain implicit and explicit assumptions about the way the agent's world operates. An important area for further research is to investigate whether complex adaptive systems theory can provide a sound theoretical grounding for the lessons drawn in this research, for Multiview, and for IS development in general. 


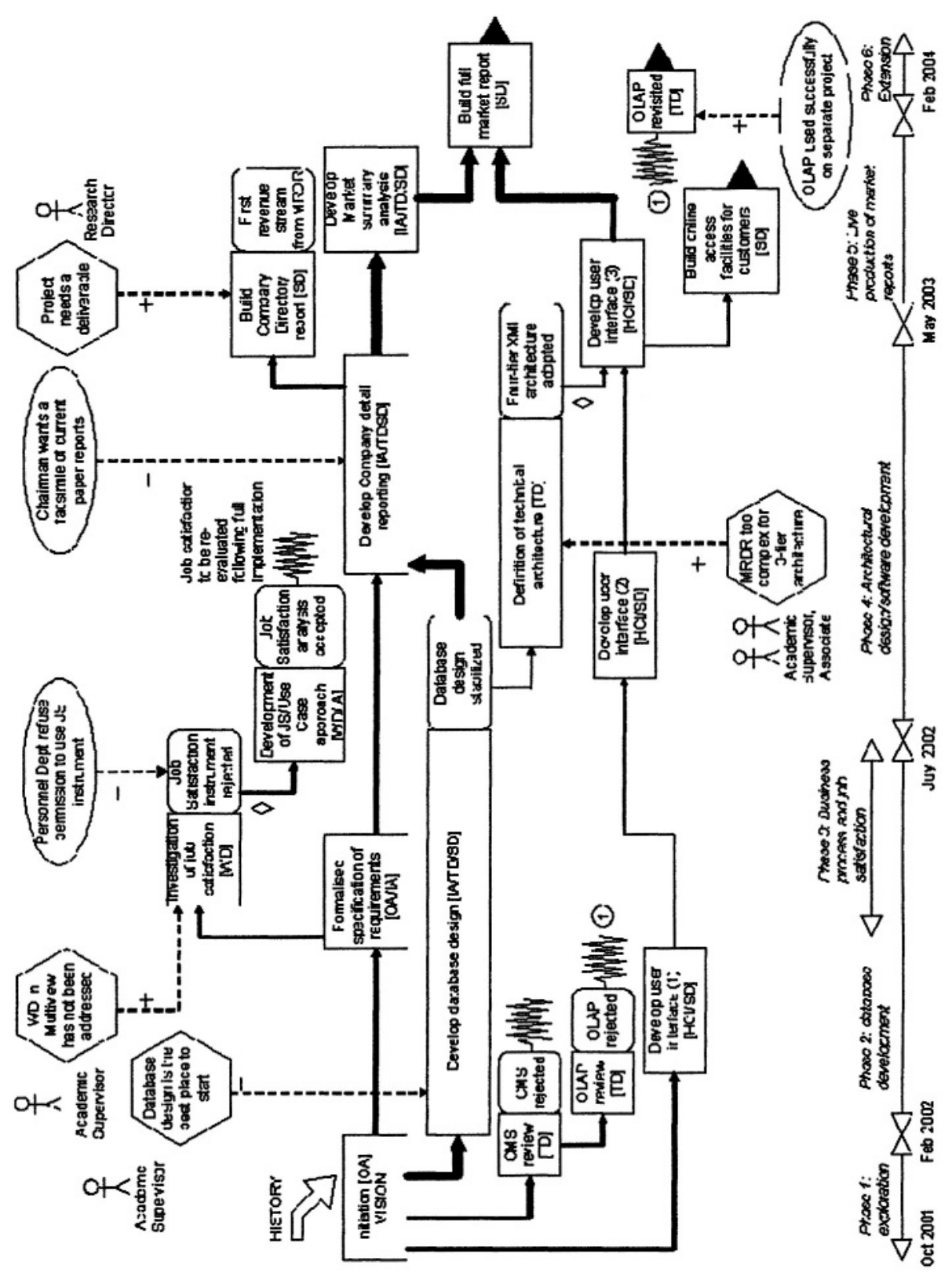

Figure 2. Process map of the unfolding MRDR development methodology 


\section{REFERENCES}

Avison, D. E., Lau, F., Myers, M. and Nielsen, P. A. (1999). Action Research. Communications of the ACM, 42 (1), 94-97.

Avison, D. E. and Fitzgerald, G. (2002), Information System Development: Methodologies, Techniques, and Tools, McGraw-Hill, Maidenhead.

Avison, D. E. and Wood-Harper, A. T. (1990). Multiview: An Exploration in Information Systems Development, McGraw Hill, Maidenhead.

Avison, D. E., Wood-Harper, A. T., Vidgen, R. T. and Wood, J. R. G. (1998). A Further Exploration into Information Systems Development: the evolution of Multiview 2. Information, Technology \& People, 11 (2), 124-139.

Baskerville, R. and Pries-Heje, J. (2001). Racing the e-bomb: How the Internet is Redefining Information Systems Development. In: Realigning Research and Practice in Information System Development, (Eds, Russo, L., Fitzgerald, B. and DeGross, J.), IFIP TC8/WG8.2 Working Conference, Boise, Idaho, USA, July 27-29

Baskerville, R. and Wood-Harper, A. T. (1996). A Critical Perspective on Action Research as a Method for Information Systems Research. Journal of Information Technology, 11235 246.

Braa, K. and Vidgen, R. (1999). Interpretation, intervention and reduction in the organizational laboratory: a framework for in-context information systems research. Accounting, Management \& Information Technology, 9 (1), 25-47.

Brown, S., and K. Eisenhardt (1998). Competing on the Edge of Chaos. Harvard Business School Press, Boston.

Checkland, P. (1981). Systems Thinking, Systems Practice, Wiley, Chichester.

Checkland, P. (1991). From Framework through Experience to Learning: the essential nature of Action Research. In: Information Systems Research: Contemporary Approaches and Emergent Traditions, (Eds, Nissen, H.-E., Klein, H. K. and Hirschheim, R.), North Hoalland, Amsterdam.

Emery, F. E. and Trist, E. L. (1960). Socio-Technical Systems. In: Management Sciences, Models and Techniques, Vol. 2 (Eds, Churchman, C. W. and Verhulst, M.), Pergamon, pp. 83-97, Oxford.

Davison, R., Martinsons, M., and Kock, N. (2004). Principles of Canonical Action Research. Information Systems Journal, 14, pp. 65-86.

Fitzgerald B. (1997), The use of Systems Development Methodologies in Practice: A Field Study, Information Systems Journal, 7(3), pp. 201-212.

Goodwin, S. and Vidgen, R., (2002). Content, Content, Everywhere ... Time to Stop and Think? The Process of Web Content Management. IEEE Computing and Control Engineering Journal, 13(2): 66-70.

Highsmith, J., (2000), Adaptive Software Development: a collaborative approach to managing complex systems, Dorset House, NY.

Highsmith, J. (2002). Agile Software Development Ecosystems, Addison-Wesley, Boston.

Jacobsen I., Booch G. and Rumbaugh J. (1999), The Unified Software Development Process, Addison-Wesley.

Kaplan, R., \& Norton, D., (1993). Putting the Balanced Scorecard to Work. Harvard Business Review, Sept-Oct, 134-147.

Langley, A., and Truax, J., (1994). A process study of new technology adoption in smaller manufacturing firms. Journal of Management Studies, 31 (5): 619-652.

Lewin, K. (1948). Resolving Social Conflicts, Harper, New York.

Miles, M., and Huberman, A., (1984). Qualitative Data Analysis. Sage, CA. 
Stolterman E. (1994), The 'transfer of rationality', acceptability, adaptability and transparency of methods, Proceedings of the 2nd European Conference on Information Systems (ECIS), Nijehrode University Press, Breukeln, pp. 533-540.

Streatfield, P., (2001). The Paradox of Control in Organizations. Routledge, London.

Thorp, J., (1998). The Information Paradox. McGraw-Hill, Montreal.

Truex, D. P., Baskerville, R. and Travis, J. (2000). Amethodical Systems Development: the deferred meaning of systems development methods. Accounting, Management and Information Technology, 10 (1), 53-79.

Vidgen, R. (2002). WISDM: Constructing a Web Information System Development Methodology. Information Systems Journal, 12 247-261.

Vidgen, R., Avison, D.E., Wood, R., and Wood-Harper, A.T. (2003), Developing Web Information Systems, Butterworth-Heinemann.

Vidgen, R., \& Madsen, S., (2003). Exploring the Socio-Technical Dimension of Information System Development: use cases and job satisfaction. In: Proceedings of the 11th European Conference on Information Systems, Naples, Italy, June 19-21.

Watson, H. and Wood-Harper, A. T. (1995). Methodology as Metaphor: The Practical Basis for Multiview Methodology (a reply to M. C. Jackson). Information Systems Journal, 5 (1), 225-231.

Wood-Harper, A. T., Antill, L. and Avison, D. E. (1985), Information Systems Definition: the Multiview Approach, Blackwell Scientific Publications, Oxford. 